\title{
Features of the construction of buildings in karst areas
}

\author{
Alexey Glushkov ${ }^{1 *}$, Vyacheslav Glushkov ${ }^{1}$, and Ilya Glushkov ${ }^{2}$ \\ ${ }^{1}$ Volga State University of Technology, 3 Lenin sq., Yoshkar-Ola, Russian Federation \\ ${ }^{2}$ Perm National Research Polytechnic University, 29 Komsomolsky prospekt, Perm, Russian \\ Federation
}

\begin{abstract}
The building of the indoor swimming pool is built in unfavorable engineering and geological conditions in the presence of karst rocks in the base. The analysis of the geological and hydrogeological conditions of the site is carried out. Calculations are made for the possible manifestation of karst in the elastic-plastic formulation. Comprehensive measures have been developed to ensure the strength and stability of the building, taking into account the possible manifestation of karst.
\end{abstract}

\section{Introduction}

The building of the indoor swimming pool is being built on a karst-prone area $50 \mathrm{~m}$ from Lake Yalchik. There was a need to estimate the engineering-geological and hydrogeological conditions of the site for the purpose of possible manifestation and influence of karst processes on the stability of the building under construction [1].

\section{Engineering-geological and hydrogeological conditions}

\subsection{Lithological conditions}

In geomorphological terms, the survey site belongs to the Ilet denudation-accumulative plain, the boundaries of which practically coincide with the contours of the modern Ilet River Valley.

In the geological structure of the territory taking part survey of modern sediments, alluvial Quaternary sediments and eluvial Upper Permian sediments.

Specific soils on the territory of the survey include eluvial soils, represented by gray fractured medium-mature low-strength limestone (Soil-5, 6, 7, 8, 9, 10, 11). Eluvial soils are the weathering crust of Upper Permian rocks [2].

From the surface to the studied depth of $115.0 \mathrm{~m}$, the geological and lithological structure is represented by the following engineering and geological section:

\footnotetext{
* Corresponding author: 256289@list.ru
} 


\begin{tabular}{|c|c|c|c|c|}
\hline \multirow{2}{*}{$\begin{array}{c}\text { Geo- } \\
\text { logical } \\
\text { age }\end{array}$} & \multirow{2}{*}{$\begin{array}{c}\text { Soil } \\
\#\end{array}$} & \multirow[t]{2}{*}{ Description of soils } & \multicolumn{2}{|c|}{$\begin{array}{c}\text { Layer } \\
\text { thickness, } \mathrm{m}\end{array}$} \\
\hline & & & from & to \\
\hline $\mathrm{tQ}_{\mathrm{IV}}$ & 1 & $\begin{array}{l}\text { Bulk soils are represented by dumps of sand, crushed stone and gravel } \\
\text { of carbonate rocks }\end{array}$ & 0.2 & 0.4 \\
\hline $\mathrm{aQ}$ & 2 & $\begin{array}{l}\text { The sand is yellow, fine, in layers of medium size, medium density, } \\
\text { low-moisture }\end{array}$ & 1.0 & 1.2 \\
\hline $\mathrm{aQ}$ & 3 & The sand is yellow, fine, in layers of medium size, dense, low-moisture & 5.3 & 6.0 \\
\hline $\mathrm{aQ}$ & 4 & $\begin{array}{l}\text { The sand is yellow, fine, in layers of medium size, dense, water- } \\
\text { saturated }\end{array}$ & 9.5 & 9.9 \\
\hline \multirow{5}{*}{$\mathrm{eP}_{2} \mathrm{kz}_{2}$} & 5 & Limestone gray fractured medium-mature, low-strength & 0.5 & 11.5 \\
\hline & 6 & Clay is a hard-plastic gray color with layers and lenses of fine sand & \multicolumn{2}{|c|}{4.0} \\
\hline & 7 & The clay is solid gray in color, with layers of sandstones & 4.0 & 40.0 \\
\hline & 8 & $\begin{array}{l}\text { Sandstone of very low strength, medium density, softened, medium- } \\
\text { matured }\end{array}$ & \multicolumn{2}{|c|}{5.5} \\
\hline & 9 & $\begin{array}{l}\text { The sand is gravelly, water-saturated, of medium density, with } \\
\text { inclusions of crushed limestone }\end{array}$ & 5.0 & 5.5 \\
\hline $\mathrm{eP}_{2} \mathrm{kz}_{1}$ & 10 & $\begin{array}{l}\text { Gypsum of medium strength, dense bluish-gray color, non-softened, } \\
\text { slightly matured }\end{array}$ & \multicolumn{2}{|c|}{17.5} \\
\hline $\mathrm{eP}_{1} \mathrm{~s}$ & 11 & $\begin{array}{l}\text { Dolomite is strong, very dense, gray, non-softened, slightly mature, } \\
\text { fractured, the cracks are filled with clay, weakly cavernous, the caverns } \\
\text { are covered with calcite crystals, dolomite with layers of clay and } \\
\text { limestone }\end{array}$ & 3.0 & 9.0 \\
\hline
\end{tabular}

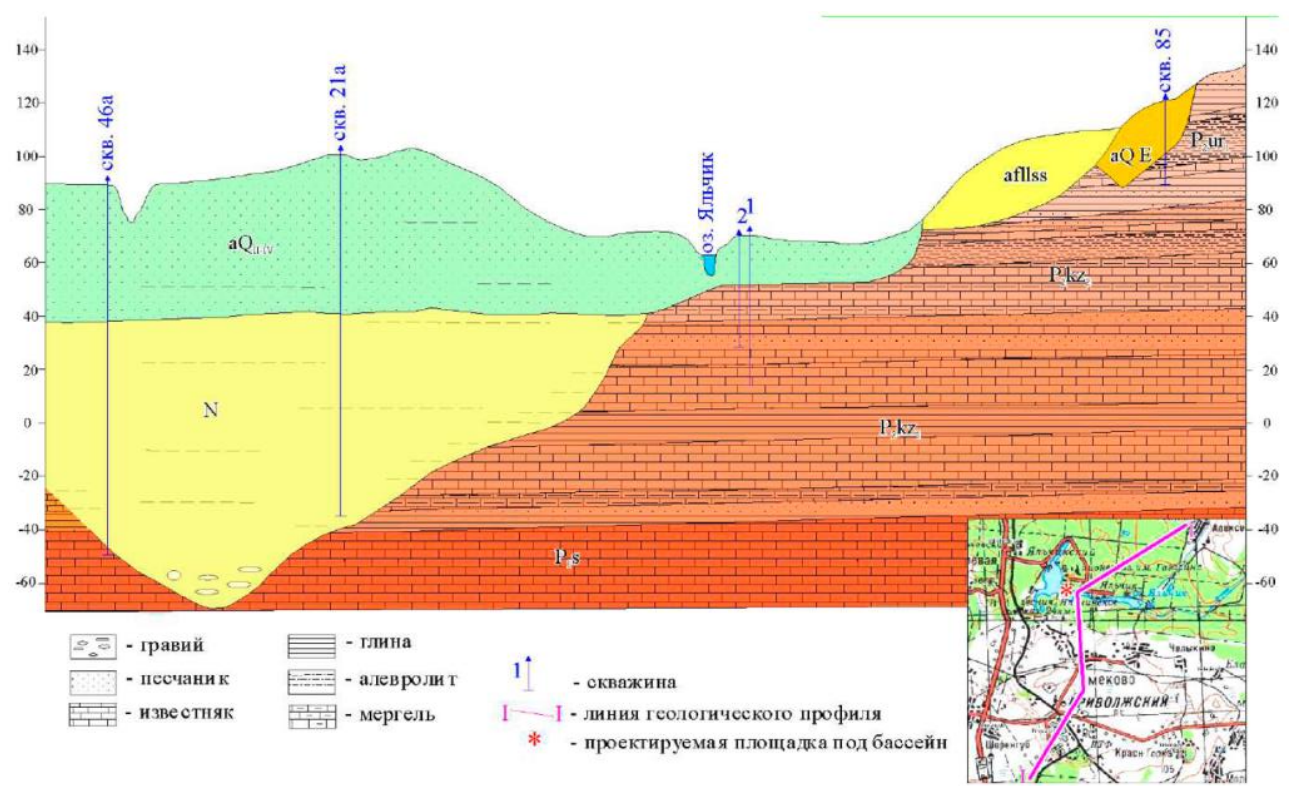

Fig. 1. Geological profile 


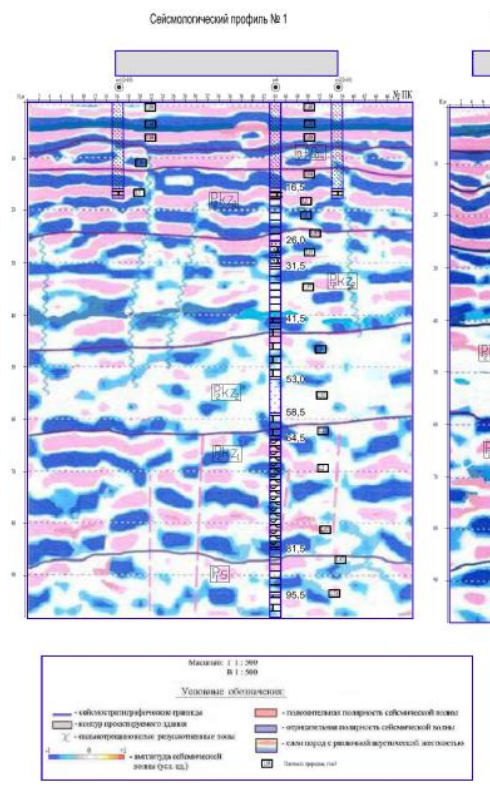

Fig. 2. Seismological profiles

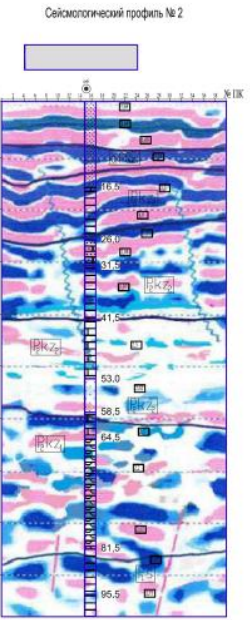

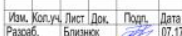

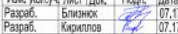

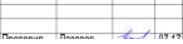

\subsection{Hydrogeological conditions}

Underground waters are uncovered at depths of 6.5-7.0 m, the aquifer is unpressurized. The thickness of the exposed watered layer is $11.0-11.5 \mathrm{~m}$. The water-bearing soils are fine dense sand Soil-4 and fractured limestone Soil-5. The level of the underground aquifer is hydraulically connected to the water level in Lake Yalchik.

The aquifer, confined to the terrigenous-carbonate deposits of the Kazan stage of the Permian system, was established at a depth of $38.0 \mathrm{~m}$. Underground waters of the Kazan tier have a sporadic distribution, they are confined to the interlayers of fractured, weathered carbonate rocks with local water resistance (interlayers of clay and gypsum). The total capacity of the aquifer according to the well drilling data is $28.0 \mathrm{~m}$. The filtration coefficient of aquifers according to the express pumping data was $6.34 \mathrm{~m}^{3} /$ day.

The Sakmara aquifer was discovered at a depth of $81.5 \mathrm{~m}$, the steady level was recorded at a depth of $18.0 \mathrm{~m}$, the water pressure was $63.5 \mathrm{~m}$. The aquifer is mainly confined to the fractured roof rocks of the Sakmara tier and to the fractured sandstone zones that lie at the base of the Lower Kazanian tier. The local water barrier is the interlayers of clays. The filtration coefficient of aquiferous soils according to the express pumping data was 3.79 $\mathrm{m}^{3} /$ day.

According to the results of the survey, the site has developed a covered type of carbonate and sulfate karst, confined to the Upper-Kazanian and lower-Kazanian deposits of the Permian system, where there are favorable conditions for the development of karst.

The construction site is located at a distance of $50 \mathrm{~m}$ from Lake Yalchik. The hollows of Lake Yalchik are "young", recently formed karst sinkholes filled with water, the banks are asymmetrical: one is flat, the other is steep. Several dozen sinkholes were recorded in the nearby area. The size of karst craters varies from $7 \mathrm{~m}$ to $70 \mathrm{~m}$. The last karst-suffusion deformation of the surface at the Yalchinsky karst site was recorded in 2000. Between the southwestern end of Lake Yalchik and the railway track, there was a karst-suffusion sinkhole measuring approximately 150 by $250 \mathrm{~m}$ and $7 \mathrm{~m}$ deep [3-6]. 
When drilling a karstological well with a depth of $115.0 \mathrm{~m}$ under a layer of Quaternary sands at depths of 16.4-16.6 $\mathrm{m}$ and in the depth range of 41.5-53.0 m, karst Upper Kazanian carbonate deposits (gray fractured limestone, medium-mature, low-strength) were uncovered, and karst gypsum was uncovered in the depth range of 64.0-81.5 m.

\subsection{Prognosis of karst processes}

According to the data of geophysical studies, the survey area is characterized by rather complex and heterogeneous kinematic and dynamic properties of wave fields, which, accordingly, are signs of an inhomogeneous physical state and structural structure of the studied rock mass $[5,7]$.

The upper part of the section is represented by water-permeable sandy soils subject to suffusion processes. The upper aquifer does not have a high-quality water barrier, it is closely connected with the soils of the Kazan tier, unloading into layers of fractured sandstone and weathered fractured carbonate rocks .

Carbonate rocks (interlayers 16.5-18.0 and 41.5 - 53.0 m) are strongly mature, not strong. The carbonate rocks are aquiferous, and the karst process is in the development stage.

The condition of the rocks covering the gypsum $(58.5-64.0 \mathrm{~m})$ is strongly eroded, aquiferous limestones.

Sulphate rocks (gypsum) were uncovered in the depth range of $64.0-81.5 \mathrm{~m}$. The condition of the gypsum is satisfactory (cracked gypsum, hairline cracks, filled with clay material). Gypsum is water-resistant. Karst processes in the gypsum layer during the survey period are weak.

According to the results of the research, the karst rocks at the survey site are carbonate rocks of the Upper Kazansky sub-stage. The section reveals favorable conditions for the development of karst: geological-lithological, hydrogeological.

The construction site of the indoor swimming pool belongs to category II of the intensity of sinkholes and to category A in terms of the diameter of the sinkholes $(>20 \mathrm{~m})$ $[8,9]$. Construction on such territories is allowed as an exception if there is a special justification for the possible reliable protection of structures from karst phenomena and the feasibility of their construction, taking into account the costs of anti-karst measures (adj. E CR 116.13330.2012).

\section{Calculations of the basis for the development of karst}

\subsection{Calculation of the possibility of failure formation}

The possibility of sinkhole formation in the sand column is calculated. The volume of the "accumulative capacity" can be determined by the formula [10]

$$
\mathrm{V}_{\mathrm{a}}=\mathrm{V}_{\mathrm{M}}\left(\mathrm{K}_{\mathrm{k}}+\mathrm{v}_{\mathrm{k}} \Delta \mathrm{t} / \Delta \mathrm{h}\right)
$$

where $\mathrm{V}_{\mathrm{M}}, \Delta \mathrm{h}$ is the volume of the rock mass, or area of accumulation, which may be deposited clastic material, and its height $\left(\mathrm{V}_{\mathrm{M}} / \Delta \mathrm{h}-\right.$ it is the average area); $\mathrm{K}_{\mathrm{k}}-$ ratio open fracture-karst voidness; $\mathrm{v}_{\mathrm{k}}-$ speed karst denudation; $\Delta \mathrm{t}$ - the period of time that is usually taken as the service life of buildings and constructions $(\Delta t=T)$. 


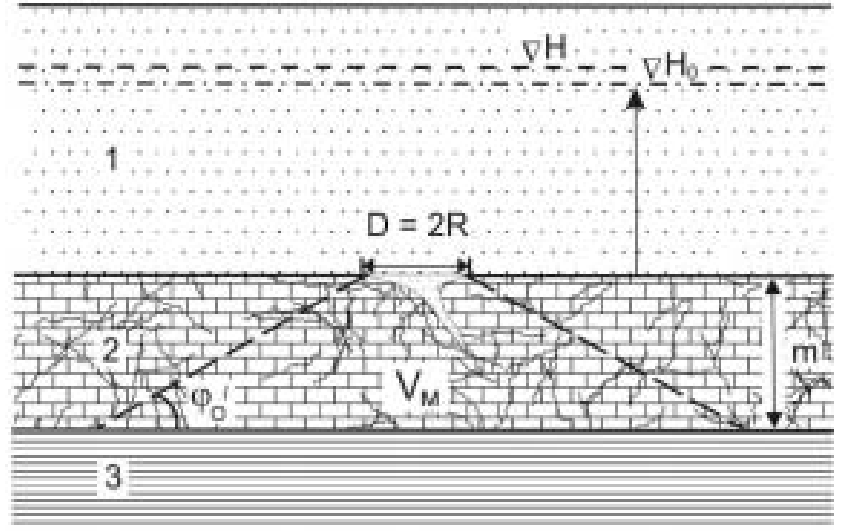

Fig. 3. To determine the accumulative capacity of soluble rocks:

1-sand, 2 - strongly fractured limestones, 3-refractory clays,

$\mathrm{H}>\mathrm{H} 0$ - ground and crack-karst water levels, $\mathrm{D}=2 \mathrm{R}$ is the diameter of the weakened area, $\varphi_{0}$ is the angle of repose for sand under water, $\mathrm{Vm}$ - the conical accumulation region.

Since the volume of the accumulative capacity $\mathrm{Va}$ is less than the critical volume Vcr, the collapse of the soil thickness above Soil-5 (limestone) is unlikely.

\subsection{Elastic-plastic calculation of the possibility of collapse of the soil mass}

The possibility of collapse of the ground mass due to the potential formation of a cavity in the limestone layer of Soil 5 in the depth range of 41.5-64 $\mathrm{m}$ is calculated [10-13].

The calculation was performed using the Plaxis geotechnical complex. The ground base was modeled as a layered structure with the specified physical and mechanical properties (density, angle of internal friction, adhesion, modulus of deformation). The cavity was modeled as a cylinder with a variable diameter. The calculation task is to determine the critical diameter of the cavity, at which the development of plastic flow zones occurs in the array above the cavity, the value of the critical diameter is $18 \mathrm{~m} \mathrm{[13].}$

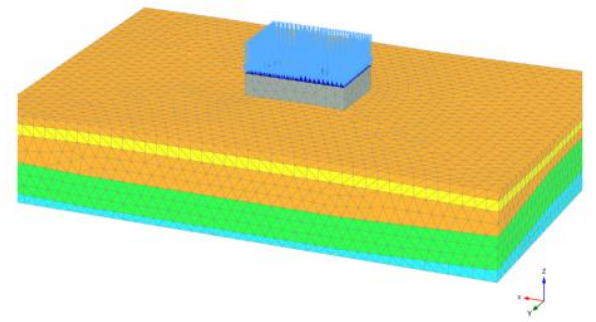

Fig. 4. Design scheme of the geomechanical model of the foundation

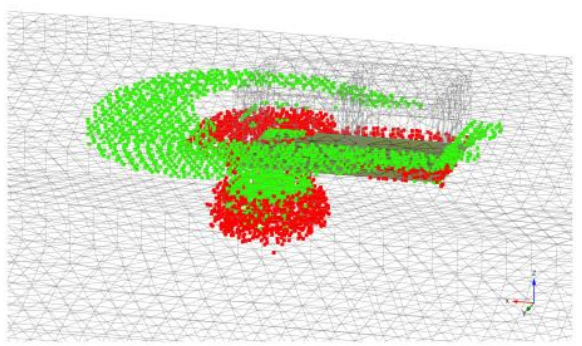

Fig. 5. Plastic points in a karst cavity under the building: red - plastic flow, green - soil stretching 


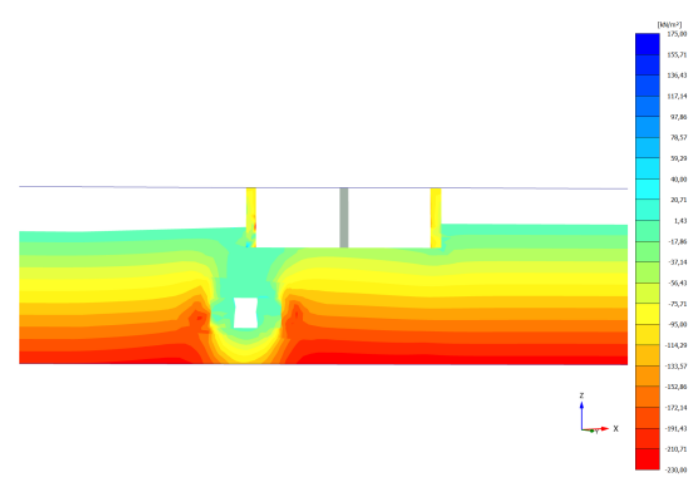

Fig. 6. Vertical stresses in the base as a result of the formation of a karst cavity in the section

Thus, in the existing engineering and geological conditions, only a carbonate karst may appear, due to the presence of a layer of limestone Soil-5 in the depth range of 16.5-18.0 m.

Sulphate karst (associated with Soil-10 gypsum) is not possible for the following reasons •

- Soil-10 is located below the regional karst base;

- no cavities were found during the survey;

- the identified cracks are hair-sized and healed with clay;

- flow rates are negligible under existing hydrogeological conditions;

- mineralization of underground water can not lead to the dissolution of rocks.

The manifestation of the karst process in the upper part of the section (up to a depth of $18.0 \mathrm{~m}$ ) is possible only in the form of a suffusion of sandy soils into the cracks and cavities of the Soil-5 limestone. This is facilitated by the presence of the "fractured limestone-sand" contact in the depth range of $16.2-16.5 \mathrm{~m}$. However, the probability of activating the process is very low.

\section{Design features of the building}

\subsection{Structural solution of the building}

The building of the indoor swimming pool with brick load-bearing walls is constructed of layered masonry. The foundations of the building are made on a natural foundation, made of monolithic concrete. At the base of the foundations lies the soil Soil-3 sand is fine, dense. The average pressure under the sole of the foundations $\mathrm{p}=220 \mathrm{kPa}$, does not exceed the calculated resistance of the soil $\mathrm{R}=460 \mathrm{kPa}$.

The ceiling and covering are made of monolithic reinforced concrete slabs on metal beams [10-12].

\section{Anti-karst measures}

When constructing a swimming pool building, the following anti-karst measures are used for engineering protection of buildings and structures from karst [10-12].

\subsection{Water protection and anti-filtration measures}

At the construction site of the building, measures are provided to regulate surface runoff. This is provided by the vertical layout of the territory with the drainage of surface water 
outside the site. The organization of drainage of rain and meltwater into drainage systems is provided

Prevention of leaks from water-carrying communications during operation. Protection of water-bearing communications from corrosion, compliance with the necessary slopes of non-pressure pipelines, ensuring the reliability of water-bearing pipelines under the conditions of exposure to external loads, Sewerage networks are laid in cases of polymer pipes.

\subsection{Constructive activities}

As the foundation of the building, a monolithic reinforced concrete in the form of crossbelts, designed taking into account the calculated span of the failure, is adopted. To ensure the necessary rigidity and strength of the foundations in the edge sections of the building, cantilever extensions of the foundations outside the pool building are adopted.

In the construction of brick walls, to increase the spatial rigidity and reliability of the above-foundation part of the building, a reinforced monolithic reinforced concrete belt is provided at the floor level. Additional reinforcement of the corners, and the additional grid of reinforcing bars under in-situ reinforced concrete belts.

\subsection{Technological measures}

Dynamic impact on the foundation soil during construction and operation is prohibited.

\subsection{Operational measures}

During the operation of the building, monitoring and visual control of the deformations of the earth's surface and the appearance of deformations in the structures of the building is organized.

Instrumental control over the deformations of the earth's surface, the appearance of deformations in the structures of the building using marks, benchmarks, etc.

Monitoring of the ground water level and changes in its chemical composition. Organization of timely receipt of information on the activation of karst processes (the Regional Center of the GMSN for the Volga Federal District, http://www.geomonitoring.ru).

\section{Conclusions}

The spatial rigidity of the building is provided by the joint work of brick walls with the device of monolithic reinforced concrete belts around the perimeter of the building, foundations and hard disks of floors.

Thus, the proposed comprehensive measures ensure the protection of the building under construction from the consequences of possible manifestations of karst phenomena that pose a threat of harm to human life and health.

\section{References}

1. Code of Rules 22.13330.2016. Soil Bases of Buildings and Structures (Moscow, 2017)

2. N. I. Kuznetsov and M. A. Solovyova, editors, State Geological Map of the Russian Federation at a Scale of 1:200 000 with an Explanatory Note. Second Edition. Srednevolzhskaya Series (2003) 
3. V. P. Homenko, Regularities and Forecast of Suffusion Processes (GEOS, Moscow, 2003)

4. PNIIS, editor, Guide to Engineering and Geological Surveys in Karst Development Areas (Moscow, 1995)

5. N. N. Lapteva, Surface and Underground Karst Forms of the Mari ASSR and Their Genetic Series (1974)

6. V. V. Tolmachev, Scheme of Development of Dangerous Karst-Suffusion Processes in the Republic of Mari El, Scale 1: 400000 (Dzerjhinsk, 1997)

7. M. V. Leonenko and V. V. Tolmachev, in Proc. Annu. Sess. Sci. Counc. Russ. Acad. Sci. Probl. Geoecology, Eng. Geol. Hydrogeol. (Moscow, 2002)

8. M. V. Leonenko, Report "Karst Hazard Assessment and Proposals for Measures to Ensure Operational Safety in the Emergency Section of the Sinkhole on the $24 \mathrm{Km}$ Railway Line Zeleny Dol-Yoshkar-Ola» (2000)

9. Recommendations for Engineering Surveys, Design, Construction and Operation of Buildings and Structures in the Karst Territories of the Nizhny Novgorod Region (Nizhny Novgorod, 2012)

10. V. V. Tolmachev and F. Roiter, Engineering Karst Studies (Moscow, 1990)

11. V. P. Homenko, Eng. Geol. 4, 40 (2009)

12. B. M. Das, Principles of Foundation Engineering (2011)

13. N. Z. Gotman and M. A. Kayumov, Soils Found. 4, (2013) 